$$
\text { رئيس مجلس الإدارة و عمبد الكلية }
$$

رئيس التحرير ووكيل الكلية للار اسات العليا والبحوث

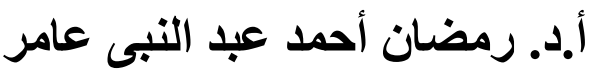

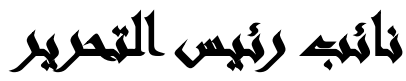

أ.م.د. مها أحمد إبراهيم

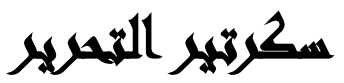

د. منال سيد محمد

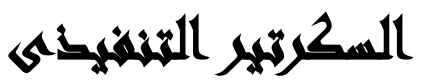

أ.محمد ربيع عبد الظاهر

المس لالمجان اللغوهيان

أ.د. أحمد عبد الللاه الشيمي

أ. محمد عبد الفتاح عبد الفهاه

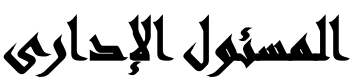

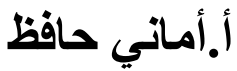

أ.حنان محمد محمود

المسئول الهاليه

أ. محمود جابر محمدين

الهيئة الاستشارية 


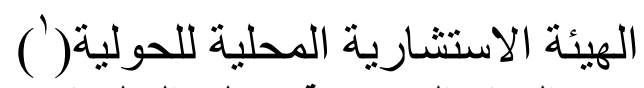

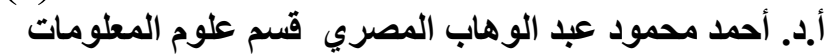

قسم علوم المطلومات

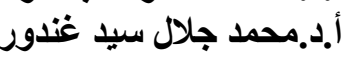
أ.د.دعصمت حسين سيد نصار قسم الفلسفة

قسم الفلسفة أ. أ.د.شعبان عبد الله محمد

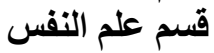

قسم اللغة الإنجليزية

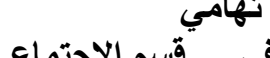

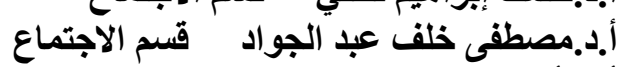

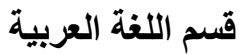

قسم اللغة العربية

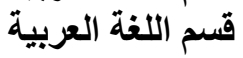

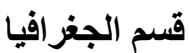

قسم الجغرافيا

قسم التاريخ

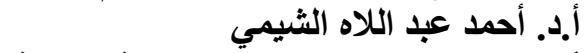

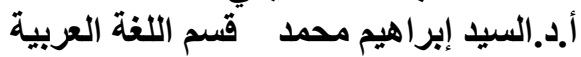

أ.أد جودة مبروك محمد مبروك ق قسم اللغة العربية

أ. أ.د.صلاح الدين حسانين

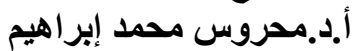

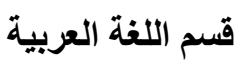

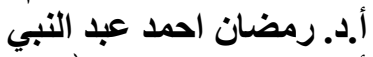

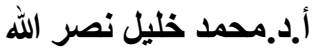

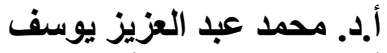

أ.د. . ـ محمد فوزي أحمد عطا سليمان

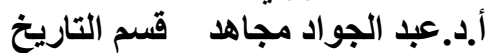

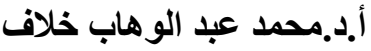

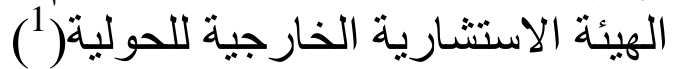

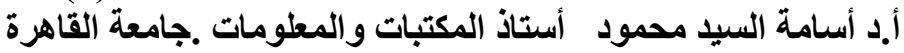

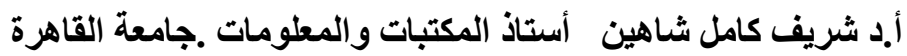

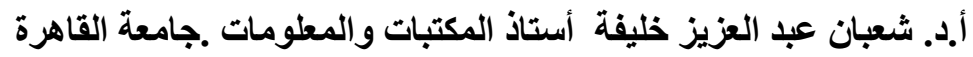

أستاذ المكتبات و المطلومات .جامعة المعات القاهرة

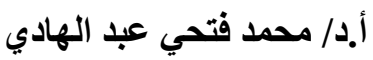

استاذ الوثائق والمطلومات - جامعة القاهرة

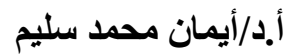

أ.د محمد عثمان الخثت أستاذ الفلسفة .جامعة القاهرة

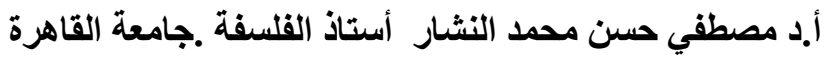

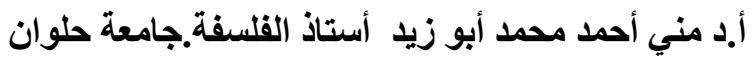

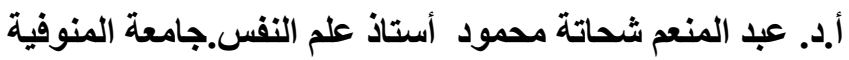

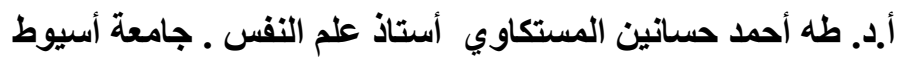

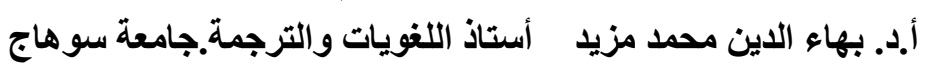

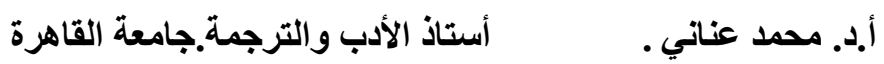

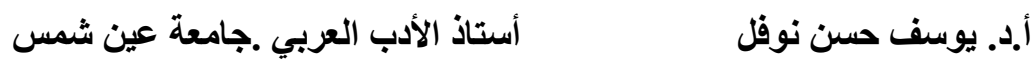

أ.د. أحمد جودة السعدني أستاذ الأدب العربي .جامعة المنيا 
أستاذ الجغرافيا الطبيعية. جامعة سوهاج أستاذ الجغرافيا.جامعة القاهرة

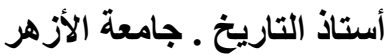
أستاذ التاريخ. جامعة المنصورة
أ.د. كريم مصلح صلاح

أ.د.شحاتة سيد أحمد مد مداف

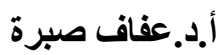

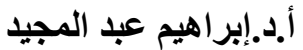

\section{همطمر العصا}

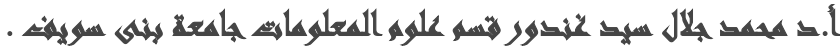

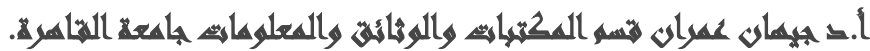

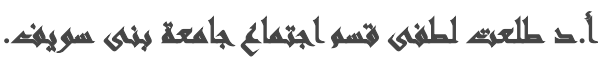

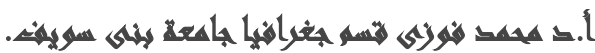

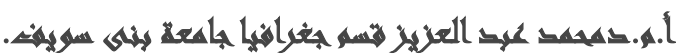

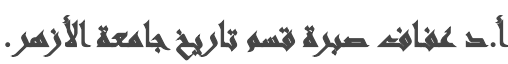

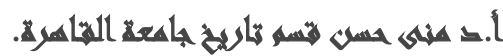

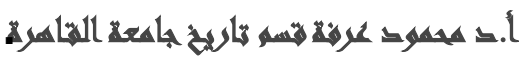


حولية كلية الآداب جامعة بني سويف حولية علمية محكمة تصدر سنوية بهدف نشر الإنتاج العلمي في مجالات العلوم الاجتماعية والسلوكية" السياسة، الاقتصاد، الاحصاء، القانون، الإدارة العامة و العلوم العسكرية، الخدمة الاجتماعية و الجمعيات الأهلية، التعليم، النقل والاتصالات والتجارة، العادات و التقاليد و آداب السلوك الك و الفلكلور " و اللغات و الآداب و الإنسانيات، وتحقيقا لهذا الغرض يُنشر في الحولية الأبحاث و الدر اسات العلمية.

وتتضمن الحولية بهانب البحوث التي يتقرر نشر ها، عروضًا للكتب حديثة الصدور في مجالات العلوم الاجتماعية و الإنسانية، كما تتضمن ملخصات و عروضًا لرسائل الماجستير و الدكتور اه المجازة من الكلية أو الكليات المناظرة، وتقارير اللقاءات العلمية (المؤتمر ات و الندوات و الحلقات العلمية). وتر اعي هيئة تحرير الحولية إتباع قو اعد التحكيم العلمي التي يجرى العمل على أساسها في المجالات العلمية وذلك لتحديد صلاحية ما يرد إليها من مقالات وبحوث. هذا وينشر كل بحث بعد موافقة كتابية على نشر البحث من محكمين على

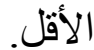




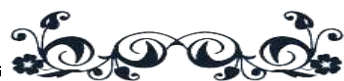

\section{قواعد النشر بالحولية}

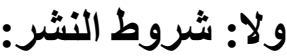

1 ـ ترحب الحولية بنشر البحوث و الدراسات العلمية التي تتسم بالأصالة والجدة، بإحدى اللغتين العربية أو الإنجليزية، شريطة أن برفق بالأبحاث والدر اسات العلمية مستخلصان، أحدهما بالعربية، والآخر بالإنجليزية ، كما تنشر التئية التقرير

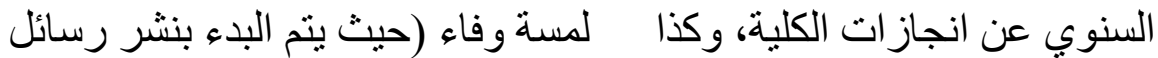
الماجستير و الدكتور اة لأعضاء هيئة التندريس الذين توفاهم الله أثناء إعدادهم لرسائلهم وذللك تكريمًا لهم وحفاظًا على حقوقهم العلمية و الأدبية.

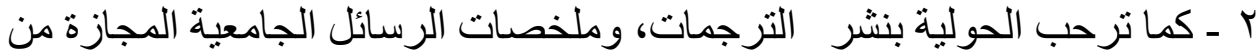
الكلية أو الكليات المناظرة، وتقارير المؤتمرات و الندوات و الحلقات الدراسية،

و عروض الكتب حديثة الصدور في مجالات العلوم الاجتماعية والإنسانية .

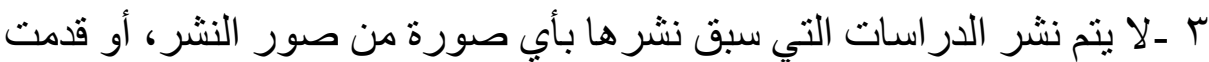
للنشر لجهة أخرى، ويُعدّ إرساله إلى الحولية تعهدًا بذللك، وفي حال قبوله لـائل للنشر في الحولية لا يسمح للباحث بنشره في مكان آخر.

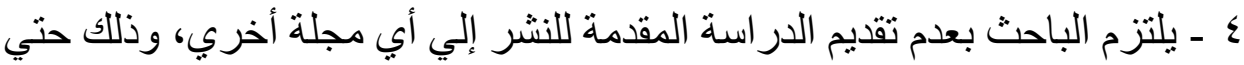

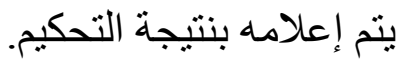
ه ـ يتحمل الباحث تكاليف تحكيم البحث سو اء قُبل للنشر أم لم يُقبل.

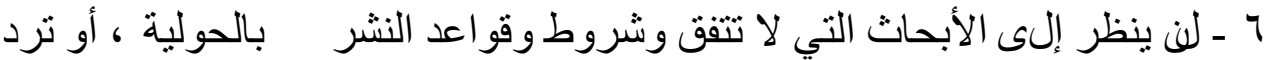
ناقصة لملخص البحث في أي من اللغتين. V - لا ترد أصول الأعمال المقدمة للحولية سواء قُّلته للنشر أم لم تُقبل.

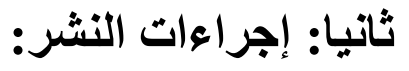

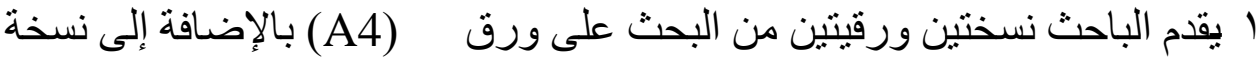
إلكترونية على CD أو عبر البريد الإلكتروني.

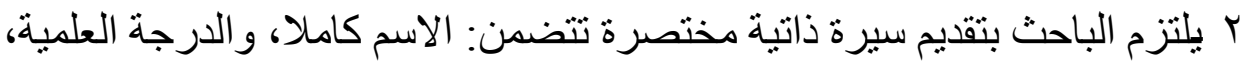
وجهة العمل، و العنوان البريدي، و البريد الإكتروني، وأرقام الهو اتف (الأرضي الإني و المحمول) و الفاكس من أجل سهولة الاتصال وسر عته. 
r تقوم هيئة التحرير بالقراءة الأولية للبحوث العلمية المقدمة للنشر بالحولية للتأكد من تو افر مقومات البحث العلمي، وترسل بعد ذللك إلى المحكمين، مع مر اعاة ما يلي:

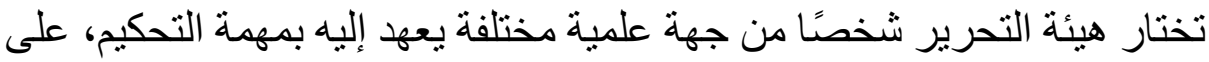
أن يكون متخصص في مجال البحث، ويفضل أن يكون بدرجة أستاذ أو أستاذ مساعد.

يرسل العمل العلمي إلى المحكمين بصفة سرية بدون ذكر اسم الباحث أو ما يدل

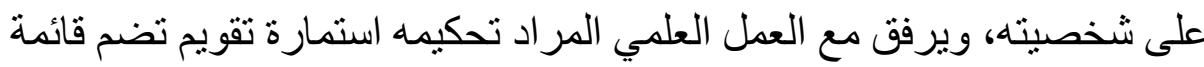

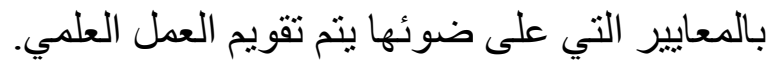
يتولى أعضاء هيئة التحرير متابعة إجر اءات التعديل و التحقق من استيفاء التعديلات المطلوبة قبل نشر العمل العلمي. يتم إبلاغ جميع الباحثين بقرار صلاحية بحوثهم للنشر من عدمه. ينشر العمل العلمي إذا اجتاز التحكيم وفق الضوابط العلمية المتعارف عليها

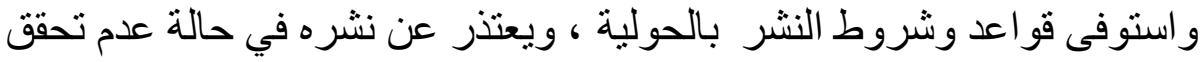
ذلك

يكتفي بالإجازة من قبل اثثين من أعضاء هيئة التحرير لنشر مر اجعات الكتب و الرسائل الجامعية وتقارير اللقاءات العلمينة.

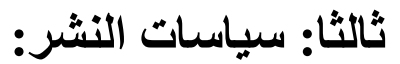

1 ـ تعطى الأولوية في النشر للبحوث و التقارير حسب الأسبقية الزمنية للورود إلى هيئة تحرير الحولية ، وذللك بعد إجازتها من قبل المحكمين، ووفقا للاعتبارات العلمية و الفنبة التي تر اها هيئة التحرير. r - يتم ترتيب الأبحاث داخل العدد موضو عيًا وفق خطة تصنيف ديوي العشري

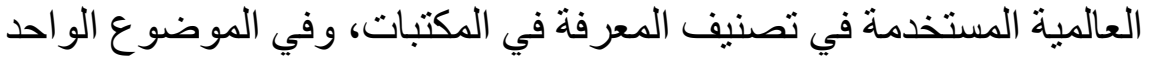
ير اعى الترتيب وفق الدرجة العلمية لصاحب العمل، ثم هجائًاً. ب بر اعى الترتيب التالي في أجز اء البحث: صفحة العنوان، المستخلص باللغة

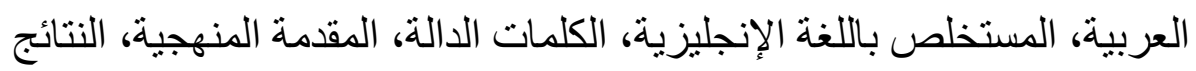
ومناقشتها، المر اجع، الأشكال و الجداول و الملاحق. 
يسجل على صفحة العنوان: عنو ان البحث في منتصف الصفحة، واسم الباحث / الباحثين متبو عًا باسم المؤسسة التي يعمل / يعملون بها، و البريد الإلكتروني

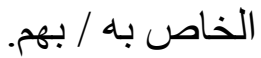

ير اعى أن يكون المستخلص في حدود 150 كلمة، وخال من الاختصار ات المنات

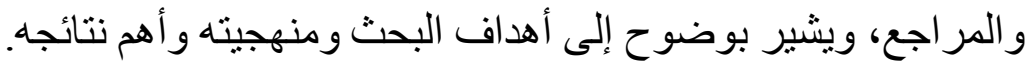

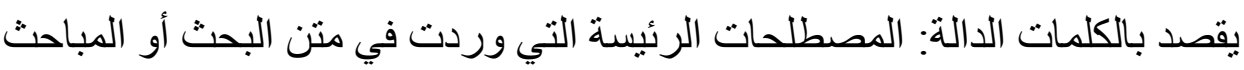
الفر عية التي تم تناولها.

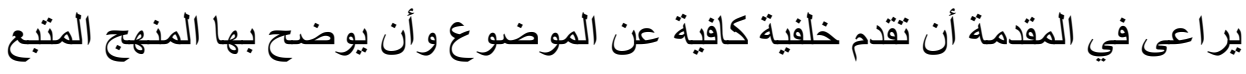

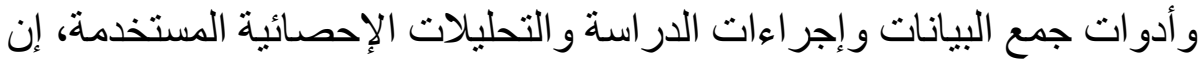
وجدت، و الدر اسات السابقة، و المثيلة. بعد المقدمة المنهجية يتم عرض النتائج التي توصل إليها الباحث، يلي ذلك مناقثنة

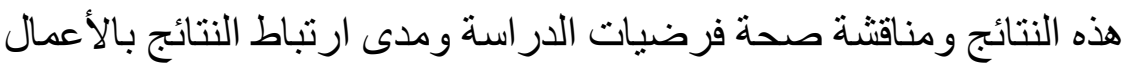

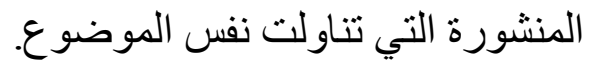
ير اعى عدم وضع الجداول الكبيرة و الأشكال التوضيحية و الخر ائط الكبيرة في منن البحث بل توضع في نهايته حتى يتمكن المر اجعون من التحكم في حجمها وفق التقال

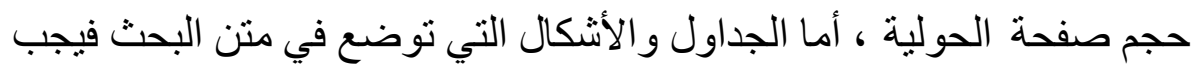

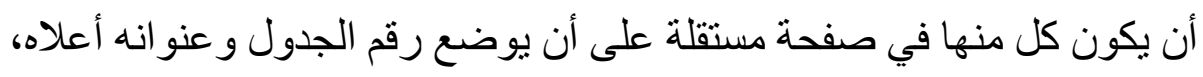

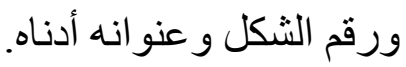

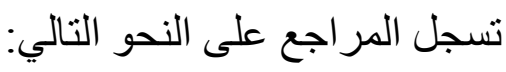

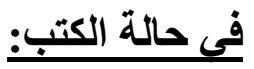
اسم المؤلف (سنة النشر). عنو ان الكتاب.-- رقم الطبعة.-- مكان النشر، اسم الناثر. في حالة مقالات الدوريات:

اسم المؤلف (سنة النشر). عنو الن المقال. - عنو ان الدوريات الدورية.-- رقم المجلد (رقم العدد)، الصفحات التي يشغلها المقال. في حالة المصدر الإلكترونى على الويب:

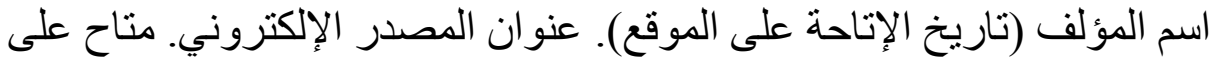
الر ابط: >يوضع الر ابط> تاريخ الاطلاع. 
رابعا: حقوق النشر:

1 - يُمنح كل باحث إفادة بقبول بحثه للنشر بعد إتمام كافة التصويبات و التعديلات

المطلوبة بعد التحكيم.

r ـ يُمنح كل باحث عشر مستلات من بحثه المنشور، بالإضافة إلى نسخة واحدة من

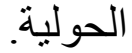

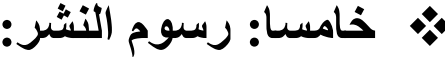

بعد قبول البحث أو الدراسة للنشر يسهم الباحث في تكاليف طباعة بحثه ونشره على

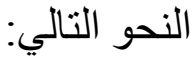

\begin{tabular}{|c|c|c|c|c|}
\hline \multicolumn{2}{|c|}{ تكلفة الصفحة } & \multirow[b]{2}{*}{ رسم تحكيم البحث } & \multirow[b]{2}{*}{ الجهة التابع لها الباحث } & \multirow[b]{2}{*}{ 5 } \\
\hline العدد الخاص & العدد الأساسى & & & \\
\hline 18 منيهات 18 مصرية & 9 جنيهات 9 & 200 : 250جنيهًا مصريًا & كلية الآداب ببني سويف & 1 \\
\hline 24 جنيهات 24 & 12 منيهات 12 & 200 : 250جنيهًا مصريًا & أعضاء هيئة التدريس & 2 \\
\hline 30 منيهًا & 15 منيهًا & 200 : 250جنيهًا مصريًا & أعضاء هيئة التـريس المعارون & 3 \\
\hline 10 دولارات أو يولها & 5 & 100 دولار أو ما يعادلها & أعضاء هيئة التدريس من كافة & 4 \\
\hline
\end{tabular}

ملحوظة : تسترد مبالغ النشر في حالة عدم قبول البحث للنشر، بعد خصم قيمة التحكيم

و المر اسلة (250 جنيهًا)

\section{سادسًا :اشتر اكات الحولية}

قيمة الاشتر الك السنوي للعدد الرئيسي كما يلي :

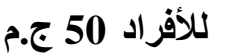

من داخل جمهورية مصر العربية :

• ل لمؤسسات 75 ج.م

• ل اللأفر اد 25 دولار، أو ما يعادلها

من خارج جمهورية مصر العربية :

•للمؤسسات 50 دولار، أو ما يعادلها 


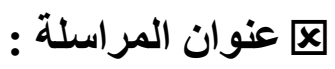

ترسل جميع المراسلات باسم رئيس تحرير الحولية على العنوان البريدي التالي:

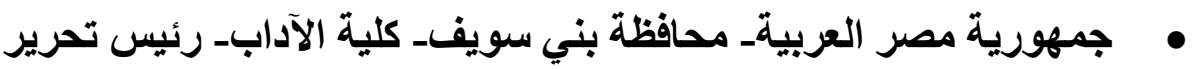

$$
\text { حولية كلية الآداب. }
$$

• أو عن طريق فاكس رقم :

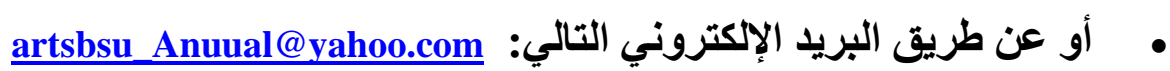


إن كلية الآداب جامعة بني سويف فى حراكها الدائب والمستمر نحو التميز، واستكمالاً لرسالتها البحثية من خلال نثر الانتاج العلمى للباحثين المصريين

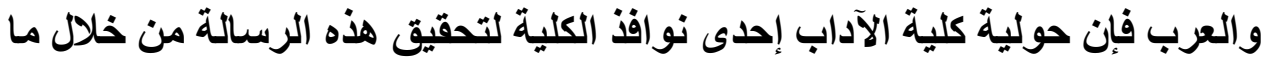
تقلمه من ابحاث علمية محكمة.

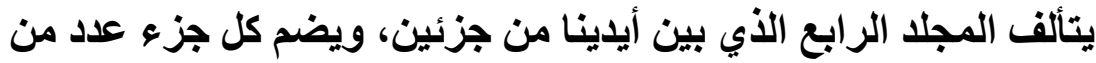
الأبحاث العلمية المتميزة لباحثين من جامعات عربية ومصرية، كما تتصف هذانه الابحاث بالتنوع فى مجالاتها. وفي السطور القادمة نأخذ القارئ في استعرض الإن الأبحاث التي يتضمنها العدد بين دفتيه. ونبدأ بالجزء الأول وفيه بحث " للاكتورة ريم علي علئ محمد الرابغى" أستاذ

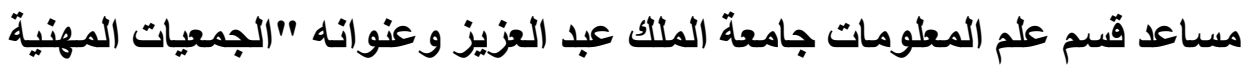

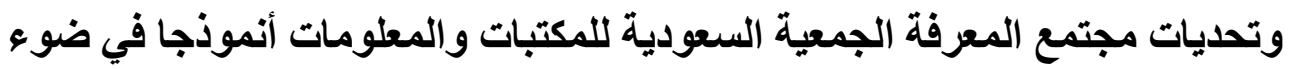

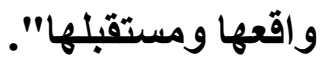
تناولت فيه الباحثة دور الجمعيات المهنية فى تخصص المكتبات في تأطير التخصص والتعريف به ودورها التكاملي مع المؤسسات الأكاديمية وسوق العمل التهل

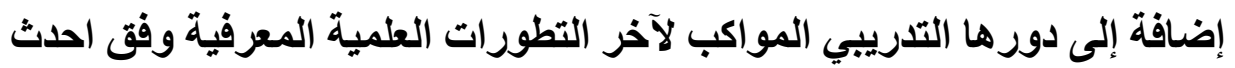
التقتيات. كما أثدارت إلى ضعف دور الجمعيات المهنية العربية استنادا إلى نتائج بعض الاراسات التى توصلت إلى ذللك، وقد ركزت الدراسة على واقد إقع جمعيات

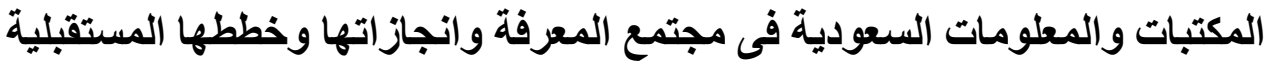

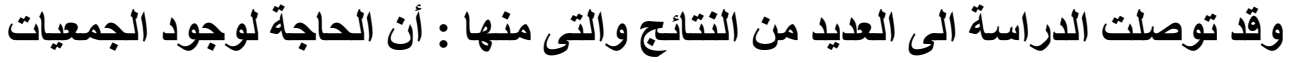

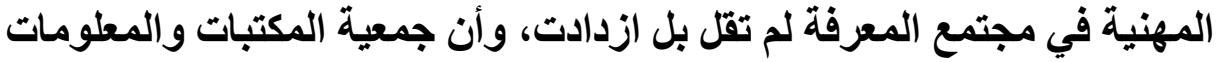

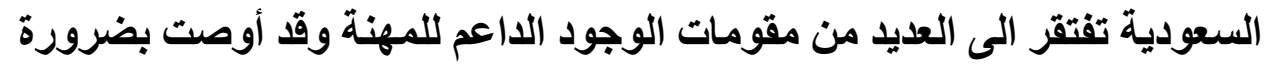

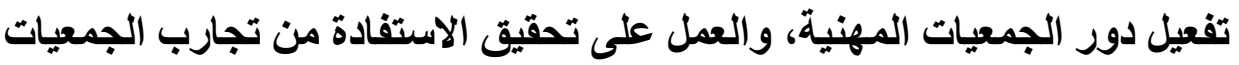
المهنية العالمية في مجال التخصص تفعيل دورالأساتذة والمستشارين والطيات والطاقيات الثبابية في تطوير أداءجمعية|لمكتبات والمعلومات السعودية. 


\section{क्ष.2:}

والبحث التالى فى مجال الوثائق "للاكتور محمد نصر عبد الحميد" مدرس الوثائق والارشيف بكلية الآداب - جامعة بني سويف و وغنوانه "استخدام الوثائق

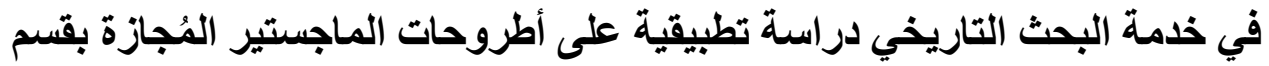

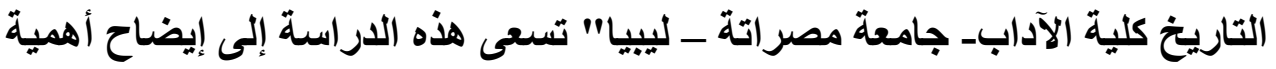

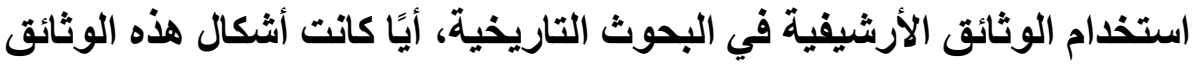

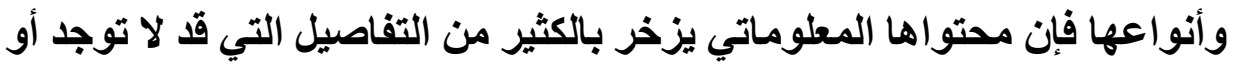

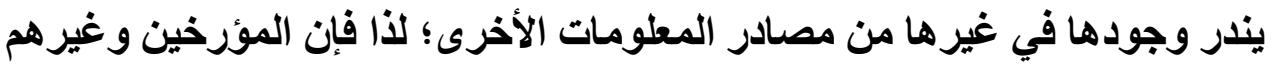

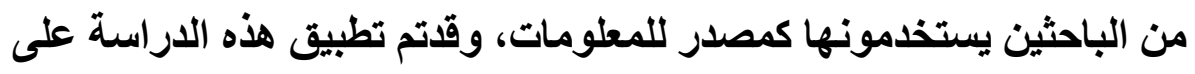

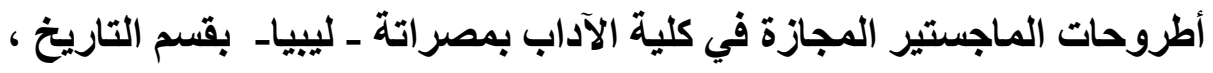

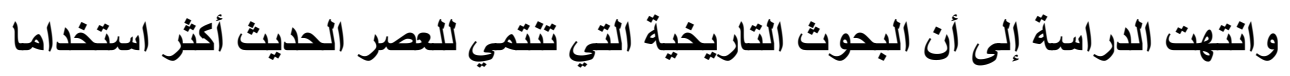

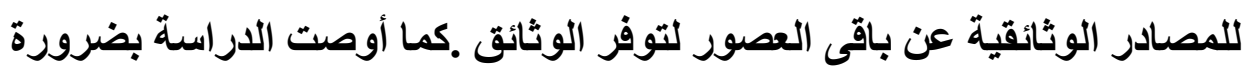

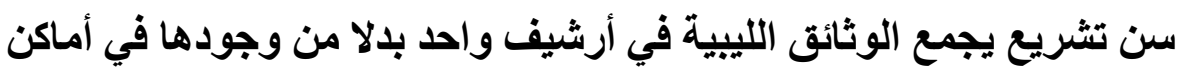
مختلفة. البحث الثالث للباحث "يونان اسحق عزيز" باحث دكتور اهو وعنوانه "أنماط

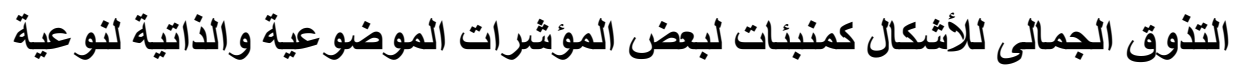

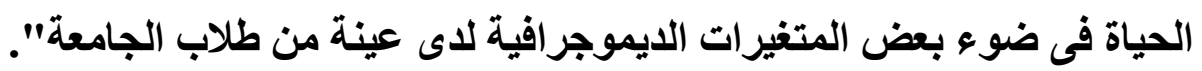

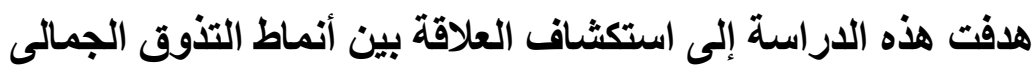

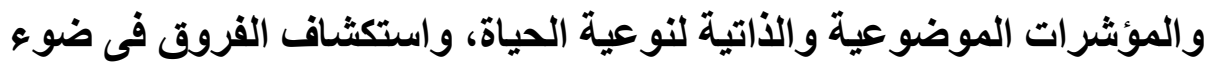

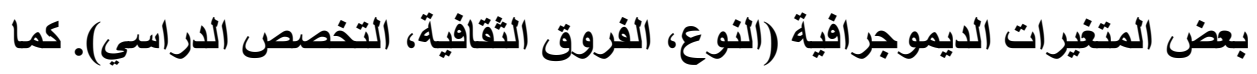

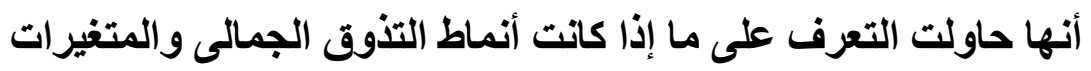

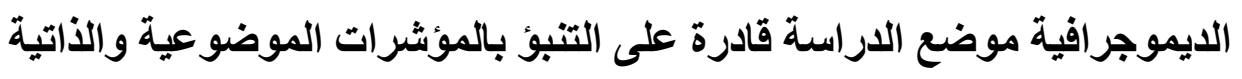

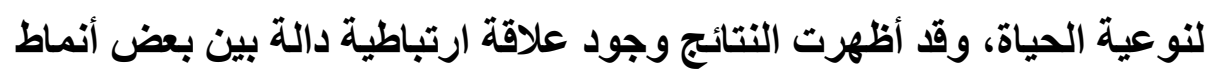

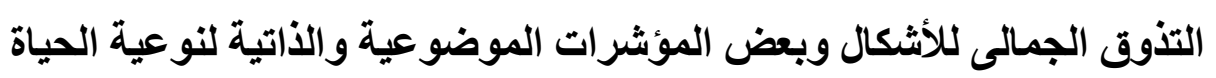

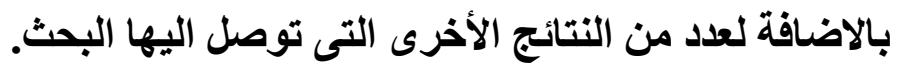

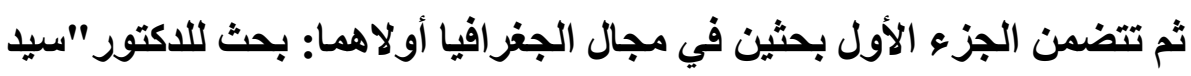

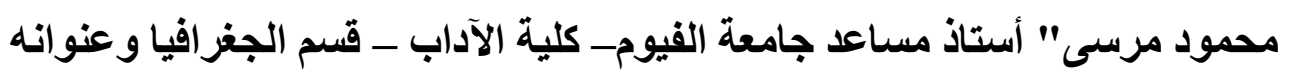

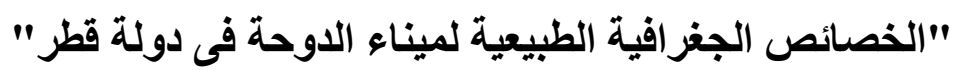




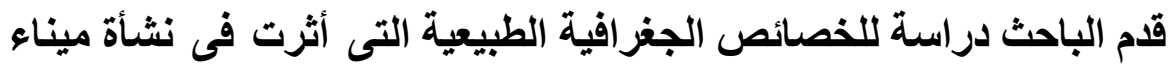

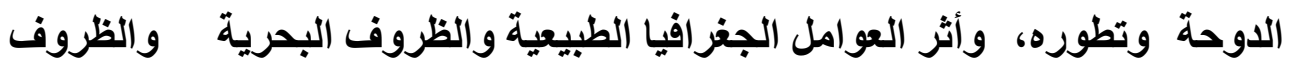

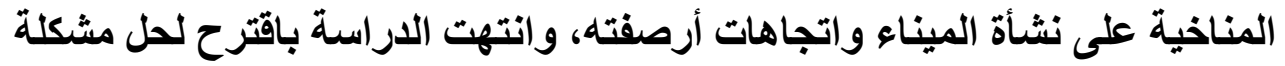
الرئيسية التى تواجه ميناء الدوحة فى الاختناقات المرورية، وتتمثل فى إنثاء ميناء جديا بعيداً عن مدينة الدوحة.

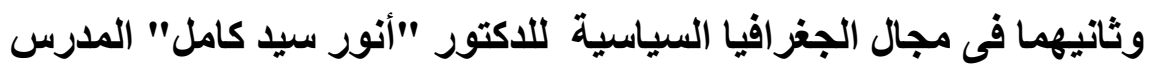

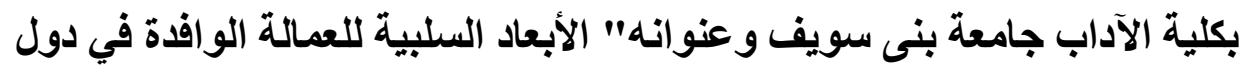
مجلس التعاون الخليجي (دراسة في الجغرافيا النيا السياسية).

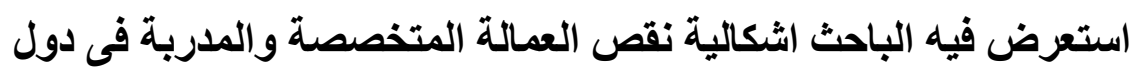

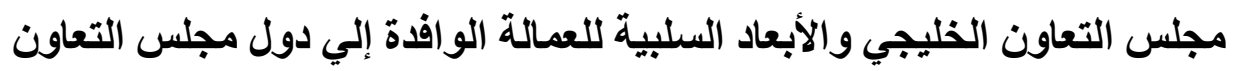

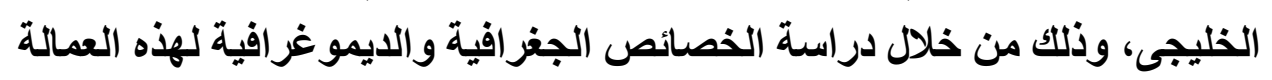

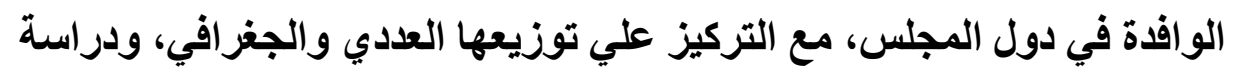

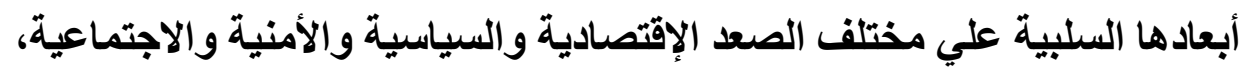

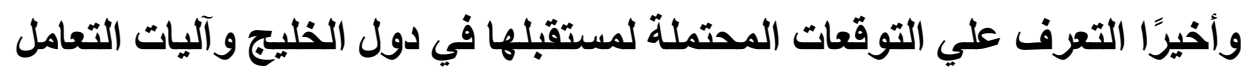
معها. ثم ننتقل إلى الجزء الثانى وبه مجموعة متميزة من الأبحاث التاريخية فتضمن

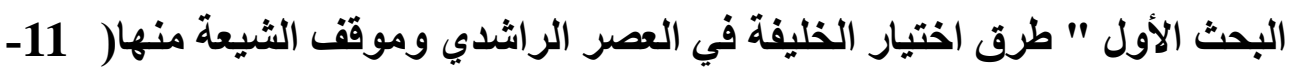

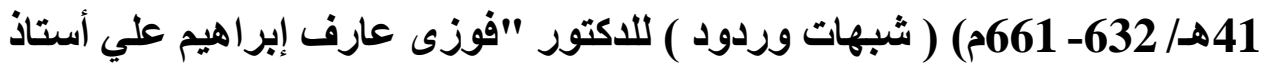

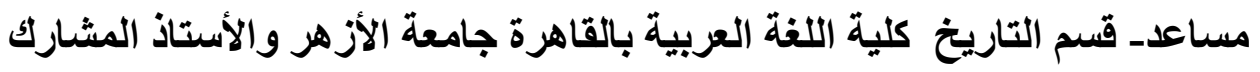

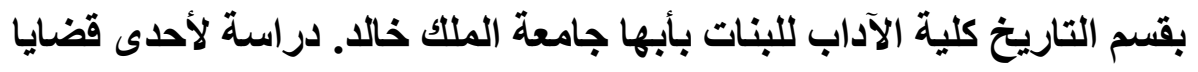

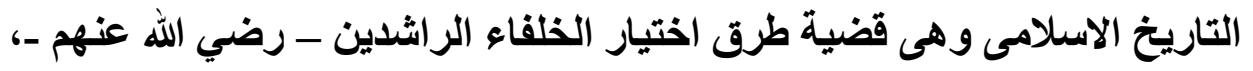

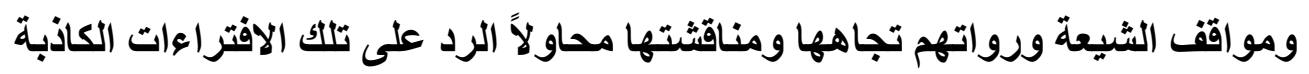

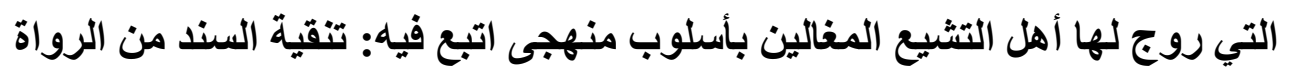

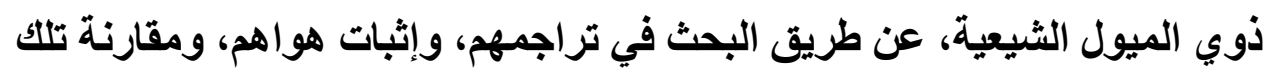

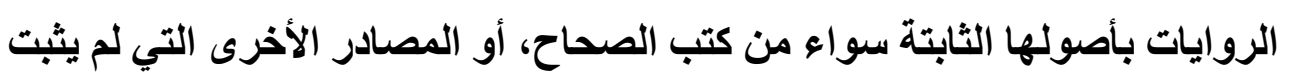

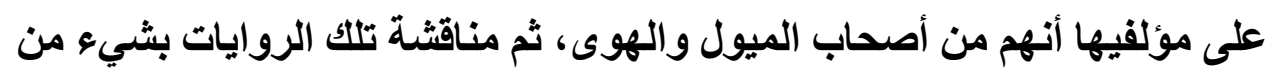

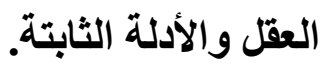


البحث التالي للاكتورة نجلاء سامي محمد النبراوي الاستاذ المساعد بكلية

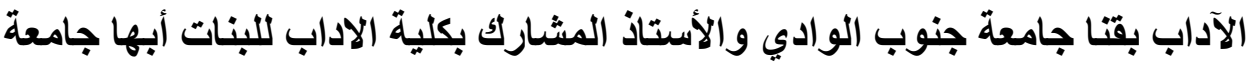

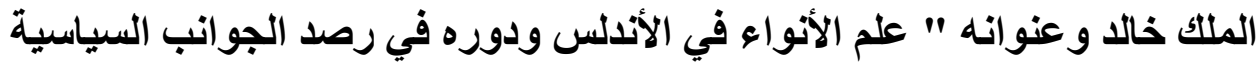

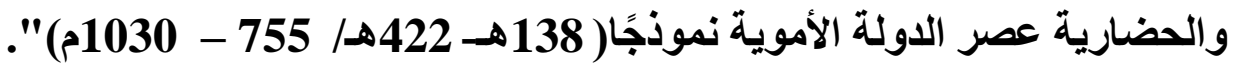
رصد هذا البحث الجوانب السياسية والحضارية في عصر الدولة الأموية

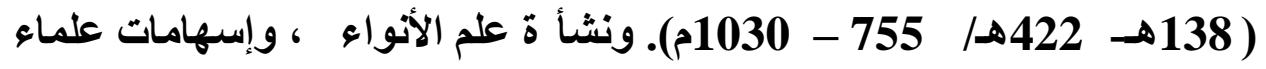

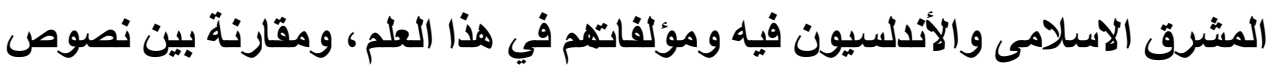

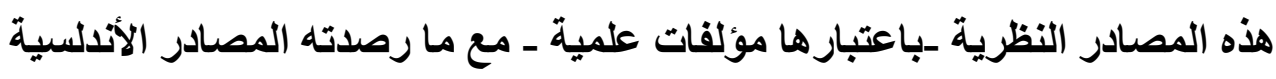

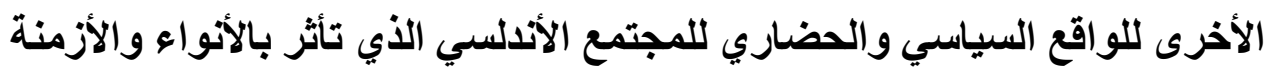
تمثيلا بعصر الاولة الأموية.

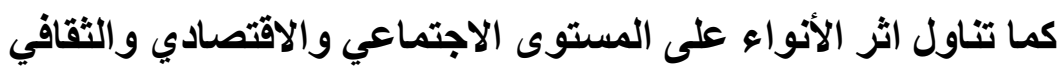

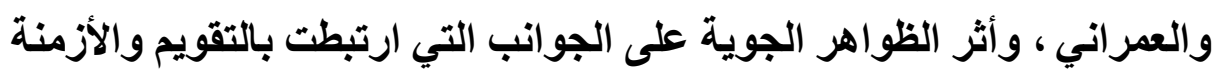

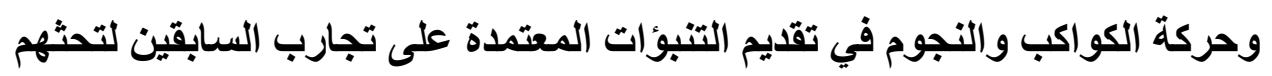

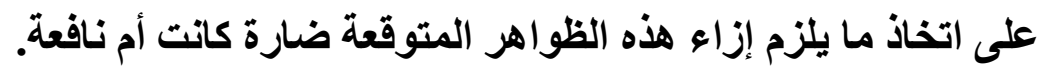

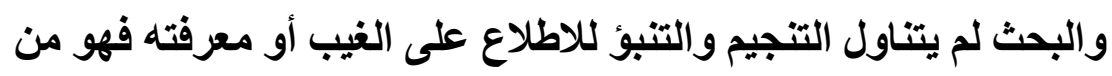

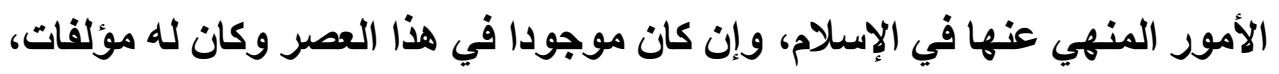
أو كان مضمونا لمؤلفات معنية بالتنجيم.

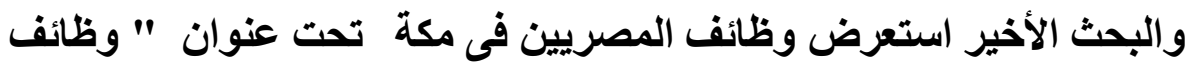

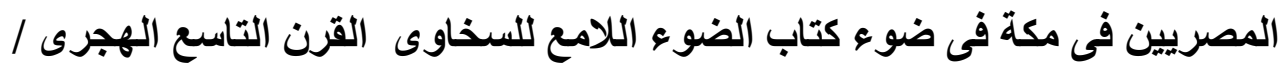

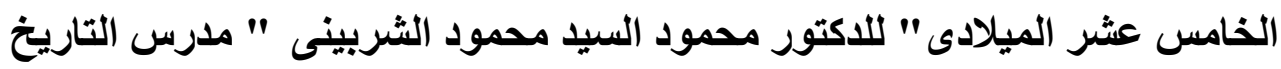

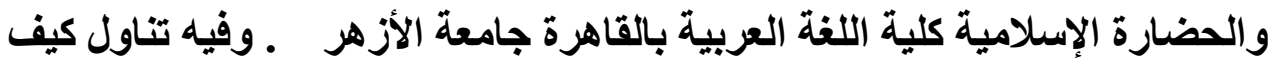
تنوعت هذه الوظائف التى تولاها المصريون ما بين وظائف دينية مثل الإمامة والخطابة والوعظ والمواعيد، والأذان، ومشيخة التصوف، والتدريس بمرحلتيه

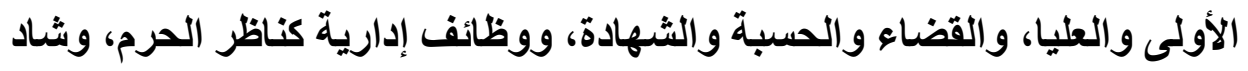

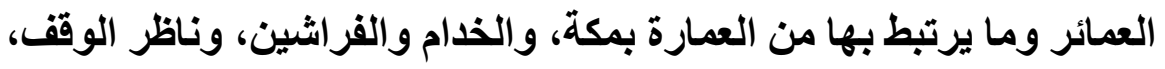
والثاهد، والسفارة، واشتهر كثير من المصريين بالكفاءة وحسن إدارة العمل، بينما 
كاتت هناك نماذج قليلة من هؤلاء الموظفين اشتهروا بالجور والظلم فى أعمالهم بحيث أصبحت سيرتهم سيئة لاى المكيين.

وفى النهاية تتقام أسرة الحولية بهذا العدد للقارئ ثقة منها بأنه سيكون

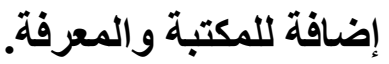

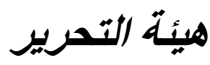




\begin{tabular}{|c|c|}
\hline $70-23$ & 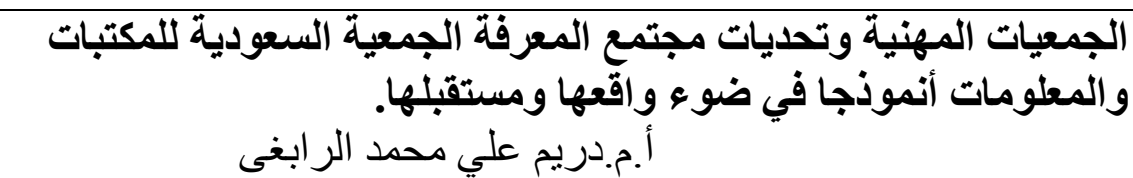 \\
\hline $\begin{array}{l}-71 \\
108\end{array}$ & 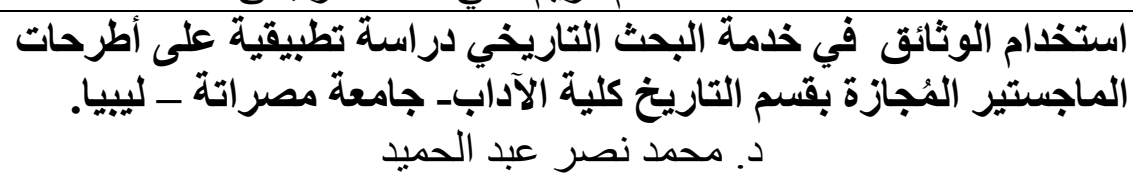 \\
\hline $\begin{array}{r}-109 \\
221\end{array}$ & 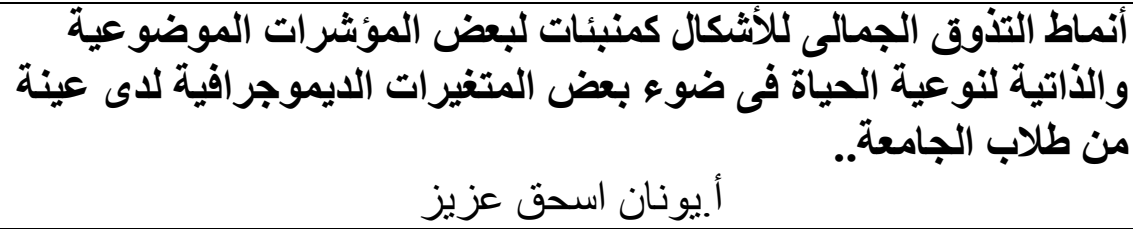 \\
\hline $\begin{array}{r}-223 \\
281 \\
\end{array}$ & 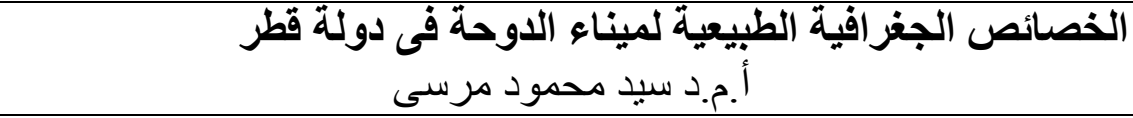 \\
\hline $\begin{array}{r}-283 \\
344\end{array}$ & 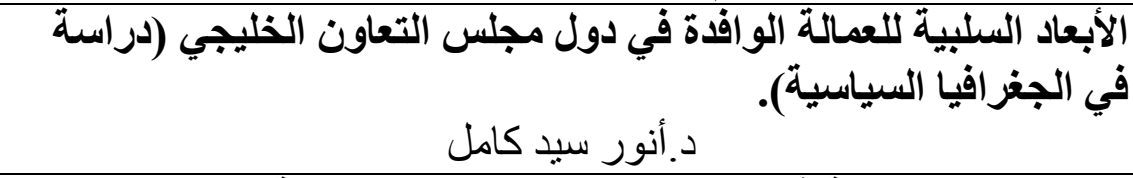 \\
\hline $\begin{array}{r}-369 \\
463\end{array}$ & 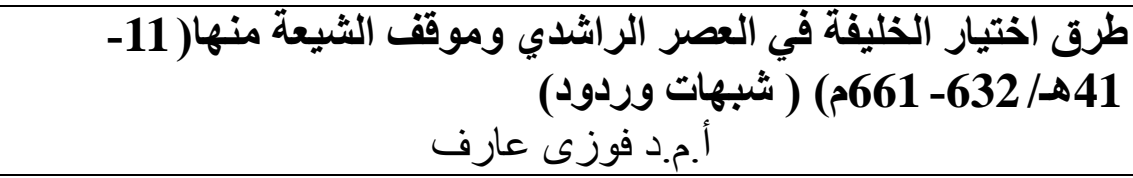 \\
\hline $\begin{array}{r}-465 \\
558\end{array}$ & 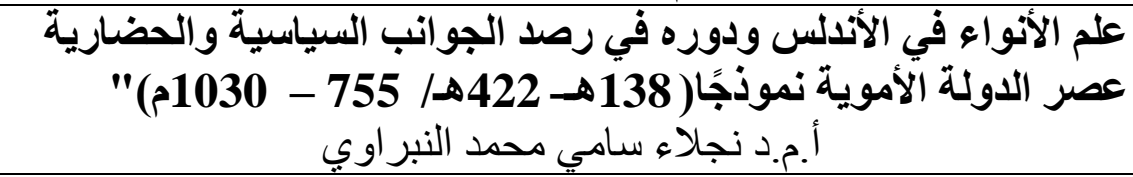 \\
\hline $\begin{array}{r}-559 \\
623\end{array}$ & 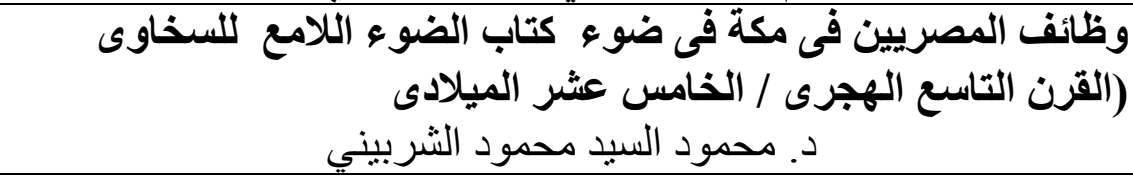 \\
\hline
\end{tabular}


20.

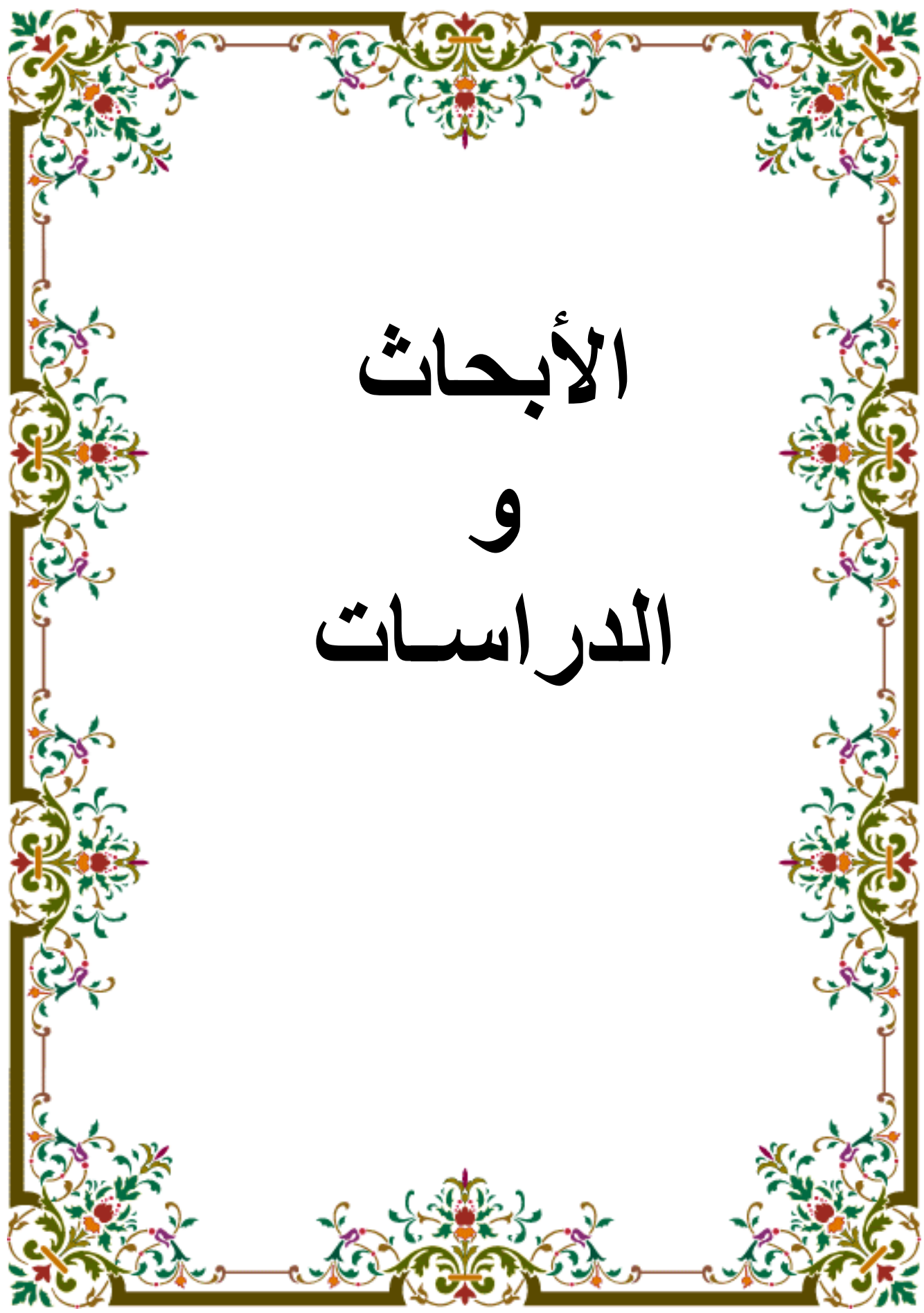


